Short Note

\title{
Menelloides C and D, New Sesquiterpenoids from the Gorgonian Coral Menella sp.
}

Shih-Yao Kao ${ }^{1,2}$, Jui-Hsin Su ${ }^{1,2,3}$, Tsong-Long Hwang ${ }^{4}$, Jyh-Horng Sheu ${ }^{3,5}$, Zhi-Hong Wen ${ }^{3,5}$, Yang-Chang Wu ${ }^{6,7, *}$ and Ping-Jyun Sung ${ }^{1,2,3,5,8, *}$

1 Institute of Marine Biotechnology, National Dong Hwa University, Pingtung 944, Taiwan;

E-Mails: sweetcloud0906@gmail.com (S.-Y.K.); x2219@nmmba.gov.tw (J.-H.S.)

2 National Museum of Marine Biology and Aquarium, Pingtung 944, Taiwan

3 Division of Marine Biotechnology, Asia-Pacific Ocean Research Center, National Sun Yat-sen

University, Kaohsiung 804, Taiwan; E-Mails: sheu@mail.nsysu.edu.tw (J.-H.S.);

wzh@mail.nsysu.edu.tw (Z.-H.W.)

4 Graduate Institute of Natural Products, Chang Gung University, Taoyuan 333, Taiwan;

E-Mail: htl@mail.cgu.edu.tw

5 Department of Marine Biotechnology and Resources, National Sun Yat-sen University, Kaohsiung 804, Taiwan

6 Graduate Institute of Integrated Medicine, College of Chinese Medicine, China Medical University, Taichung 404, Taiwan

7 Natural Medicinal Products Research Center and Center for Molecular Medicine, China Medical University Hospital, Taichung 404, Taiwan

8 Department of Life Science and Institute of Biotechnology, National Dong Hwa University, Hualien 974, Taiwan

* Authors to whom correspondence should be addressed; E-Mails: yachwu@mail.cmu.edu.tw (Y.-C.W.); pjsung@nmmba.gov.tw (P.-J.S.); Tel.: +886-8-882-5037 (P.-J.S.); Fax: +886-8-882-5087 (P.-J.S.).

Received: 20 July 2011; in revised form: 22 August 2011 / Accepted: 5 September 2011 /

Published: 14 September 2011

\begin{abstract}
Two new metabolites, including a lindenane-type sesquiterpenoid, menelloide C (1), and a germacrane-type sesquiterpenoid, menelloide D (2), were isolated from a Formosan gorgonian coral identified as Menella sp. The structures of $\mathbf{1}$ and $\mathbf{2}$ were established by spectroscopic methods and $\mathbf{2}$ displayed a weak inhibitory effect on the release of elastase by human neutrophils.
\end{abstract}

Keywords: menelloide; lindenane; germacrane; sesquiterpenoid; Menella; elastase 


\section{Introduction}

Previous chemical investigations on gorgonian corals belonging to genus Menella (family Plexauridae) [1] have yielded a series of interesting natural products [2-8]. In continuation of our search for new substances from the invertebrates collected off the waters of Taiwan, four new sesquiterpenoid derivatives, (-)-hydroxylindestrenolide (3) [9], menelloide A (4), menelloide B (5), and (+)-chloranthalactone B (6) [10] have been isolated from the gorgonian Menella sp. We have further isolated two new sesquiterpenoids, including a lindenane-type sesquiterpenoid, menelloide C (1), and a germacrane-type sesquiterpenoid, menelloide D (2) (Figure 1) from Menella sp. In this paper, we describe the isolation, structure characterization, and bioactivity of sesquiterpenoids $\mathbf{1}$ and $\mathbf{2}$.

Figure 1. The structures of menelloides C (1), D (2), (-)-hydroxylindestrenolide (3), menelloide A (4), menelloide B (5), and (+)-chloranthalactone B (6).

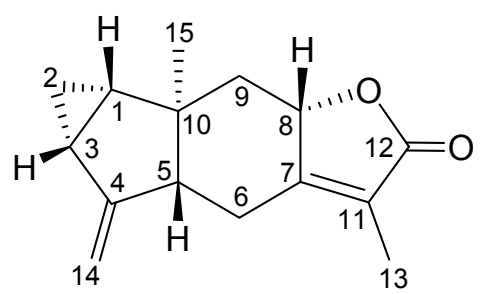

1

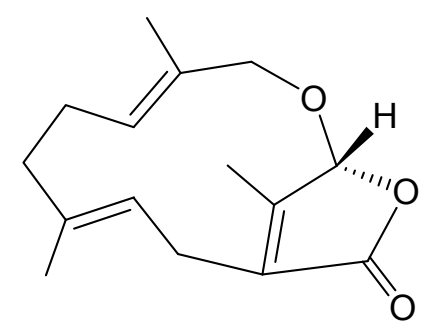

4

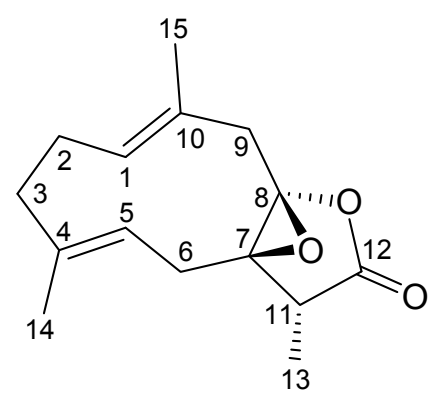

2

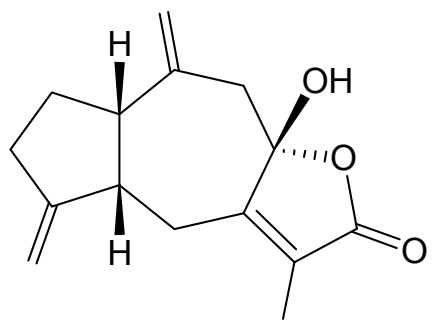

5<smiles>C=C1CC=C[C@]2(C)C[C@]3(O)OC(=O)C(C)=C3C[C@H]12</smiles>

3

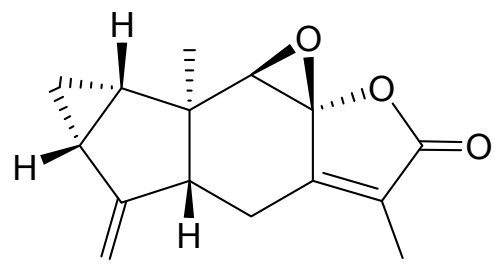

6

\section{Results and Discussion}

Menelloide C (1) was isolated as a needle solid and the molecular formula for this compound was determined to be $\mathrm{C}_{15} \mathrm{H}_{18} \mathrm{O}_{2}$ ( $7^{\circ}$ of unsaturation) using HRESIMS $\left(\mathrm{C}_{15} \mathrm{H}_{18} \mathrm{O}_{2} \mathrm{Na}, \mathrm{m} / z\right.$ 253.1206, calculated 253.1204). The IR spectrum of 1 showed a strong band at $1744 \mathrm{~cm}^{-1}$, consistent with the presence of ester group. From the ${ }^{13} \mathrm{C}$ NMR data (Table 1), a suite of resonances at $\delta_{\mathrm{C}} 174.8(\mathrm{C}-12), 162.4(\mathrm{C}-7), 122.6(\mathrm{C}-11), 78.4(\mathrm{CH}-8)$, and $8.6\left(\mathrm{CH}_{3}-13\right)$, could be assigned to the $\alpha$-methyl- $\alpha, \beta$-unsaturated- $\gamma$-lactone moiety in $\mathbf{1}$. An additional unsaturated functionality was indicated by ${ }^{13} \mathrm{C}$ NMR resonances at $\delta_{\mathrm{C}} 151.4(\mathrm{C}-4)$ and $106.6\left(\mathrm{CH}_{2}-14\right)$, suggesting the presence of an exocyclic carbon-carbon double bond. On the basis of overall unsaturation data, compound 1 was concluded to be a molecule possessing four rings.

From the ${ }^{1} \mathrm{H}-{ }^{1} \mathrm{H}$ COSY spectrum of $\mathbf{1}$ (Table 1), it was possible to differentiate between the separate spin systems of $\mathrm{H}-1 / \mathrm{H}_{2}-2 / \mathrm{H}-3, \mathrm{H}-5 / \mathrm{H}_{2}-6$, and $\mathrm{H}-8 / \mathrm{H}_{2}-9$. These data, together with the key HMBC correlations between protons and quaternary carbons of 1 , such as $\mathrm{H}-2 \beta / \mathrm{C}-4 ; \mathrm{H}-6 \alpha, \mathrm{H}_{2}-9$, 
$\mathrm{H}_{3}-13 / \mathrm{C}-7 ; \mathrm{H}-2 \beta, \mathrm{H}-9 \alpha, \mathrm{H}_{3}-15 / \mathrm{C}-10 ; \mathrm{H}_{3}-13 / \mathrm{C}-11$; and $\mathrm{H}_{3}-13 / \mathrm{C}-12$ permitted the elucidation of the carbon skeleton of 1 (Table 1). The exo-cyclic carbon-carbon double bond at $\mathrm{C}-4$ was confirmed by the $\mathrm{HMBC}$ correlations between $\mathrm{H}_{2}-14 / \mathrm{C}-5$. The vinyl methyl group at $\mathrm{C}-11$ was established by the HMBC correlations between $\mathrm{H}_{3}-13 / \mathrm{C}-7, \mathrm{C}-11, \mathrm{C}-12$. The ring junction $\mathrm{CH}_{3}-15$ was positioned at $\mathrm{C}-10$ from the HMBC correlations between $\mathrm{H}_{3}-15 / \mathrm{C}-1, \mathrm{C}-5, \mathrm{C}-9, \mathrm{C}-10$ and $\mathrm{H}_{2}-9 / \mathrm{C}-15$. Therefore, the proposed skeleton of $\mathbf{1}$ was established and suggested to be a lindenane-type sesquiterpenoid.

Table 1. NMR Spectroscopic Data (500 MHz, $\mathrm{CDCl}_{3}$ ) for Menelloide C (1).

\begin{tabular}{|c|c|c|c|c|}
\hline \multicolumn{5}{|c|}{ Menelloide C (1) } \\
\hline Position & $\delta_{\mathrm{C}}$, Mult. & $\delta_{H}(J$ in $\mathbf{H z})$ & ${ }^{1} \mathrm{H}-{ }^{1} \mathrm{H} \mathrm{COSY}$ & HMBC \\
\hline 1 & $28.9, \mathrm{CH}$ & 1.38, ddd $(7.5,7.5,3.5)$ & 2,3 & n.o. ${ }^{a}$ \\
\hline $2 \alpha$ & $16.6, \mathrm{CH}_{2}$ & $0.70, \mathrm{~m}$ & $1,2 \beta, 3$ & n.o. \\
\hline$\beta$ & & $0.84, \mathrm{~m}$ & $1,2 \alpha, 3$ & 4,10 \\
\hline 3 & $23.8, \mathrm{CH}$ & $2.02, \mathrm{~m}$ & 1,2 & n.o. \\
\hline 4 & $151.4, \mathrm{C}$ & & & \\
\hline 5 & $56.5, \mathrm{CH}$ & $3.02, \mathrm{~m}$ & 6 & n.o. \\
\hline $6 \alpha$ & $22.9, \mathrm{CH}_{2}$ & $2.35, \mathrm{dd}(18.0,12.5)$ & $5,6 \beta$ & $5,7,8$ \\
\hline$\beta$ & & $2.54, \mathrm{~m}$ & $5,6 \alpha$ & n.o. \\
\hline 7 & $162.4, \mathrm{C}$ & & & \\
\hline 8 & $78.4, \mathrm{CH}$ & $5.19, \mathrm{~m}$ & 9 & n.o. \\
\hline $9 \alpha$ & $43.3, \mathrm{CH}_{2}$ & $1.82, \mathrm{dd}(13.0,9.0)$ & $8,9 \beta$ & $5,7,8,10,15$ \\
\hline$\beta$ & & $2.62, \mathrm{dd}(13.0,11.5)$ & $8,9 \alpha$ & $7,8,15$ \\
\hline 10 & $38.9, \mathrm{C}$ & & & \\
\hline 11 & 122.6, C & & & \\
\hline 12 & $174.8, \mathrm{C}$ & & & \\
\hline 13 & $8.6, \mathrm{CH}_{3}$ & $1.82, \mathrm{~s}$ & & $7,11,12$ \\
\hline $14 \mathrm{a}$ & $106.6, \mathrm{CH}_{2}$ & $5.03, \mathrm{~s}$ & $14 b$ & 5 \\
\hline $\mathrm{b}$ & & $4.75, \mathrm{~s}$ & $14 \mathrm{a}$ & 5 \\
\hline 15 & $21.2, \mathrm{CH}_{3}$ & $0.51, \mathrm{~s}$ & & $1,5,9,10$ \\
\hline
\end{tabular}

The relative configuration of 1 was elucidated by a NOESY spectrum which was compatible with those of 1 offered by computer modeling (Table 2), in which the close contacts of atoms calculated in space were consistent with the NOESY correlations. In the NOESY experiment of 1, H-8 showed correlations with $\mathrm{H}-5$ and $\mathrm{H}-9 \beta$, indicating that these protons were situated on the same face and assigned as $\beta$-protons. Furthermore, $\mathrm{H}_{3}-15$ showed correlations with $\mathrm{H}-9 \alpha$, but not with $\mathrm{H}-5$, suggesting that $\mathrm{CH}_{3}-15$ was $\alpha$-oriented. $\mathrm{H}-1$ exhibited correlations with $\mathrm{H}-3$ and $\mathrm{H}-9 \beta$, indicating that the cyclopropane ring was positioned on the $\alpha$ face in $\mathbf{1}$. 
Table 2. The Stereoview of 1 (Generated from Computer Modeling) and the Calculated Distances $(\AA)$ between Selected Protons Having Key NOESY Correlations.

\begin{tabular}{llll}
\hline & H/H & $(\mathbf{A})$ \\
\hline
\end{tabular}

In our previous study, a lindenane-type sesquiterpenoid, (+)-chloranthalactone $\mathrm{B}(\mathbf{6})\left([\alpha]_{\mathrm{D}}^{25}+136\right.$ $\left(c 0.05, \mathrm{CHCl}_{3}\right)$ ), was isolated from this study material Menella sp. [10] and this compound was proven to be an enantiomer of a known compound, chloranthalactone $\mathrm{B}(7)([\alpha]-130.3(c 0.1, \mathrm{MeOH}))$ (Figure 2), which was isolated from the roots of Chloranthus glaber and Chloranthsu japonicus, respectively [11-13]. It was found that the structure of $\mathbf{1}$ was similar to those of lindenanes $\mathbf{6}$ and 7 except for the 8,9-epoxy group [10-12]. It is interesting to note that the lindenane-type sesquiterpenoids possessing a cyclopropane moiety, presented as structures $\mathbf{1}$ (menelloide C, $\left([\alpha]_{\mathrm{D}}^{25}+57\left(c\right.\right.$ 0.04, $\left.\left.\mathrm{CHCl}_{3}\right)\right)$ and $6((+)$-chloranthalactone B) [10], isolated from Menella sp. were suggested to possess the same configurations for the chiral carbons C-5 and C-10 because these two compounds were isolated from the same organisms.

Figure 2. The structures of chloranthalactone B (7) and shizukanolide (8).

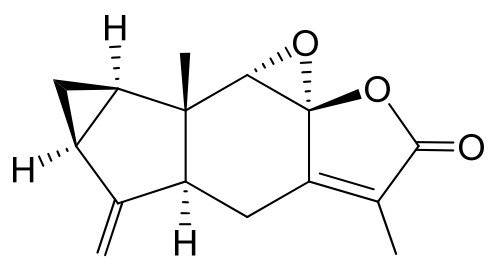

7

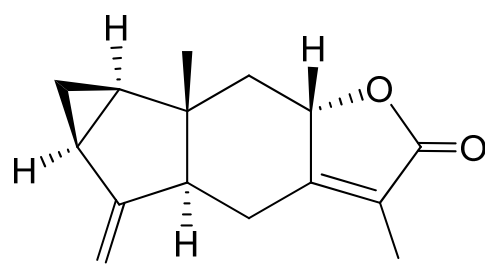

8

Moreover, the structure of $\mathbf{1}$ was compared with that of a known sesquiterpenoid metabolite, shizukanolide (8) (Figure 2), which was first isolated from a Japanese plant Chloranthus japonicus (Chloranthaceae) $[14,15]$. It was found that these two compounds possessed the same planar structures and $\mathbf{1}$ was found to be a diastereomer of shizukanolide (8) by comparison of the NMR data of $\mathbf{1}$ with those of $\mathbf{8}$.

Compound 2 (menelloide D), obtained as a colorless oil, showed an $[\mathrm{M}+\mathrm{Na}]^{+}$signal at $m / z 271.1312$ in the HRESIMS, suggesting the molecular formula $\mathrm{C}_{15} \mathrm{H}_{20} \mathrm{O}_{3}$ (calcd $\mathrm{C}_{15} \mathrm{H}_{20} \mathrm{O}_{3} \mathrm{Na}$, 271.1310), with $6^{\circ}$ of unsaturation. The IR spectrum of 2 showed a band at $1798 \mathrm{~cm}^{-1}$, consistent with the presence of $\gamma$-lactone group. The ${ }^{13} \mathrm{C}$ NMR and DEPT spectra of $\mathbf{2}$ showed that this compound has 15 carbons (Table 3), including three methyls, four $\mathrm{sp}^{3}$ methylenes, an $\mathrm{sp}^{3}$ methine, two $\mathrm{sp}^{2}$ methines, two $\mathrm{sp}^{3}$ quaternary carbons, and three $\mathrm{sp}^{2}$ quaternary carbons. From the ${ }^{1} \mathrm{H}$ and ${ }^{13} \mathrm{C}$ NMR spectra 
(Table 3), 2 was found to possess a $\gamma$-lactone moiety $\left(\delta_{\mathrm{C}} 175.6, \mathrm{C}-12\right)$ and two trisubstituted olefins $\left(\delta_{\mathrm{H}} 4.93,1 \mathrm{H}, \mathrm{dd}, J=11.0,5.0 \mathrm{~Hz}, \mathrm{H}-1 ; \delta_{\mathrm{C}} 131.3, \mathrm{C}-10 ; 129.6, \mathrm{CH}-1 ; \delta_{\mathrm{H}} 4.41,1 \mathrm{H}, \mathrm{d}, J=11.0 \mathrm{~Hz}, \mathrm{H}-5\right.$; $\left.\delta_{\mathrm{C}} 130.5, \mathrm{C}-4 ; 121.3, \mathrm{CH}-5\right)$. The presence of a tetrasubstituted epoxy group was confirmed from the signals of two oxygenated quaternary carbons at $\delta_{\mathrm{C}} 92.8(\mathrm{C}-8)$ and $71.0(\mathrm{C}-7)$ and this epoxy group could be a part of a hemiketal constellation in the $\gamma$-lactone moiety on the basis of a characteristic carbon signal at $\delta_{\mathrm{C}} 92.8$ (C). Thus, from the above data, compound $\mathbf{2}$ was identified as a tricyclic compound.

Table 3. NMR Spectroscopic Data (500 MHz, $\mathrm{CDCl}_{3}$ ) for Menelloide D (2).

\begin{tabular}{|c|c|c|c|c|}
\hline \multicolumn{5}{|c|}{ Menelloide D (2) } \\
\hline Position & $\delta_{\mathrm{C}}$, Mult. & $\delta_{H}(J$ in $\mathbf{H z})$ & ${ }^{1} \mathrm{H}_{-}{ }^{1} \mathrm{H} \mathrm{COSY}$ & НMBC $(\mathrm{H} \rightarrow \mathrm{C})$ \\
\hline 1 & $129.6, \mathrm{CH}$ & $4.93, \mathrm{dd}(11.0,5.0)$ & 2 & $2,9,15$ \\
\hline $2 \alpha$ & 26.7, $\mathrm{CH}_{2}$ & $2.03, \mathrm{~m}$ & $1,2 \beta, 3$ & $1,3,4,10$ \\
\hline$\beta$ & & $2.12, \mathrm{~m}$ & $1,2 \alpha, 3$ & n.o. ${ }^{a}$ \\
\hline $3 \alpha$ & $38.9, \mathrm{CH}_{2}$ & 2.20, ddd $(12.0,3.0,3.0)$ & $2,3 \beta$ & 1 \\
\hline$\beta$ & & $1.74, \mathrm{ddd}(12.0,12.0,4.0)$ & $2,3 \alpha$ & $1,2,4,5,14$ \\
\hline 4 & $130.5, \mathrm{C}$ & & & \\
\hline 5 & $121.3, \mathrm{CH}$ & $4.41, \mathrm{~d}(11.0)$ & 6 & 3 \\
\hline $6 \alpha$ & $25.9, \mathrm{CH}_{2}$ & $2.91, \mathrm{~d}(17.0)$ & $5,6 \beta$ & $4,5,7,8$ \\
\hline$\beta$ & & $2.62, \mathrm{dd}(17.0,11.0)$ & $5,6 \alpha$ & $4,5,7,8$ \\
\hline 7 & $71.0, \mathrm{C}$ & & & \\
\hline 8 & $92.8, \mathrm{C}$ & & & \\
\hline $9 \alpha$ & $40.6, \mathrm{CH}_{2}$ & $3.01, \mathrm{~d}(14.5)$ & $9 \beta$ & $1,8,10,15$ \\
\hline$\beta$ & & $3.14, \mathrm{~d}(14.5)$ & $9 \alpha$ & $1,7,8,10,15$ \\
\hline 10 & 131.3, C & & & \\
\hline 11 & $43.4, \mathrm{CH}$ & $2.72, \mathrm{q}(7.0)$ & 13 & $6,7,12,13$ \\
\hline 12 & $175.6, \mathrm{C}$ & & & \\
\hline 13 & $10.1, \mathrm{CH}_{3}$ & $1.36, \mathrm{~d}(7.0)$ & 11 & $7,11,12$ \\
\hline 14 & $17.0, \mathrm{CH}_{3}$ & $1.59, \mathrm{~s}$ & & $3,4,5$ \\
\hline 15 & $17.0, \mathrm{CH}_{3}$ & $1.34, \mathrm{~s}$ & & $1,9,10$ \\
\hline
\end{tabular}

From the ${ }^{1} \mathrm{H}-{ }^{1} \mathrm{H}$ COSY spectrum of 2 , three different structural units, C-1/C-2/C-3, C-5/C-6, and C-11/C-13, were identified (Table 3), which were assembled with the assistance of an HMBC experiment (Table 3). The HMBC correlations between protons and quaternary carbons such as $\mathrm{H}-2 \alpha$, $\mathrm{H}-3 \beta, \mathrm{H}_{2}-6, \mathrm{H}_{3}-14 / \mathrm{C}-4 ; \mathrm{H}_{2}-6, \mathrm{H}-9 \beta, \mathrm{H}-11, \mathrm{H}_{3}-13 / \mathrm{C}-7 ; \mathrm{H}_{2}-6, \mathrm{H}_{2}-9 / \mathrm{C}-8 ; \mathrm{H}-2 \alpha, \mathrm{H}_{2}-9, \mathrm{H}_{3}-15 / \mathrm{C}-10$; and $\mathrm{H}-11, \mathrm{H}_{3}-13 / \mathrm{C}-12$ were employed successfully to establish the planar structure of 2.

The relative stereochemistry of $\mathbf{2}$ was established on the basis of a NOESY experiment and by vicinal ${ }^{1} \mathrm{H}-{ }^{1} \mathrm{H}$ coupling constant analysis. In the NOESY experiment of 2 (Table 4), correlations observed between $\mathrm{H}_{3}-14$ and $\delta_{\mathrm{H}} 2.62$ as $\mathrm{H}-6 \beta$; and $\mathrm{H}_{3}-15$ and $\delta_{\mathrm{H}} 2.03$ as $\mathrm{H}-2 \alpha$, as well as the lack of correlation observed between $\mathrm{H}-1$ and $\mathrm{H}_{3}-15$ and $\mathrm{H}-5$ and $\mathrm{H}_{3}-14$, reflected the $E$ geometry of double bonds at C-1/10 and C-4/5. H-5 showed a NOESY correlation with $\delta_{\mathrm{H}} 2.91$ as $\mathrm{H}-6 \alpha$ and no coupling constant $(J=0.0 \mathrm{~Hz})$ was found between these two protons indicating the dihedral angle between these two protons is approximately $90^{\circ}$ by modeling analysis. $\mathrm{H}_{3}-13$ showed a correlation with $\mathrm{H}-6 \alpha$, which 
suggests that $\mathrm{H}-11$ was $\beta$-oriented in the $\gamma$-lactone moiety. Moreover, there is no correlation between $\mathrm{H}-11$ and any proton in 2 except with $\mathrm{H}_{3}-13$. Based on this finding, the epoxy group between $\mathrm{C}-7 / 8$ should be $\beta$-oriented and led to the stereohindrance between $\mathrm{H}-11$ and $\mathrm{C}-6$ methylene protons by modeling analysis.

Table 4. The Stereoview of 2 (Generated from Computer Modeling) and the Calculated Distances $(\AA)$ between Selected Protons Having Key NOESY Correlations.

\begin{tabular}{lll}
\hline Menelloide D (2) & $\mathbf{H} / \mathbf{H}$ & $(\mathbf{\AA})$ \\
\hline $\mathrm{H}-2 \alpha / \mathrm{H}_{3}-15$ & 2.50 \\
$\mathrm{H}-5 / \mathrm{H}-6 \alpha$ & 2.89 \\
$\mathrm{H}-6 \alpha / \mathrm{H}_{3}-13$ & 2.44 \\
$\mathrm{H}-6 \beta / \mathrm{H}_{3}-14$ & 2.45 \\
& & \\
& & \\
\end{tabular}

The in vitro anti-inflammatory effects of $\mathbf{2}$ were tested. Sesquiterpenoid $\mathbf{2}$ displayed a weak inhibitory effect on the release of elastase by human neutrophils (inhibition rate 10.5\%) at a concentration of $10 \mu \mathrm{g} / \mathrm{mL}$.

\section{Experimental Section}

\subsection{General Experimental Procedures}

Melting points were determined using a Fargo apparatus and were uncorrected. Optical rotations were measured on a Jasco P-1010 digital polarimeter. Infrared spectra were recorded on a Varian Diglab FTS 1000 FT-IR infrared spectrophotometer; peaks are reported in $\mathrm{cm}^{-1}$. The NMR spectra were recorded on a Varian Inova $500 \mathrm{NMR}$ spectrometer using the residual $\mathrm{CHCl}_{3}$ signal $\left(\delta_{\mathrm{H}} 7.26 \mathrm{ppm}\right)$ as an internal standard for ${ }^{1} \mathrm{H}$ NMR and $\mathrm{CDCl}_{3}\left(\delta_{\mathrm{C}} 77.1 \mathrm{ppm}\right)$ for ${ }^{13} \mathrm{C} \mathrm{NMR}$. Coupling constants $(J)$ are given in Hz. ESIMS and HRESIMS were recorded on a Bruker APEX II mass spectrometer. Column chromatography was performed on silica gel (230-400 mesh, Merck, Darmstadt, Germany). TLC was carried out on precoated Kieselgel $60 \mathrm{~F}_{254}(0.25 \mathrm{~mm}$, Merck) and spots were visualized by spraying with $10 \% \mathrm{H}_{2} \mathrm{SO}_{4}$ solution followed by heating. HPLC was performed using a system comprised of a Hitachi L-7100 pump, a Hitahci L-7455 photodiode array detector, and a Rheodyne injection port. A normal phase column (Hibar $250 \times 10 \mathrm{~mm}$, Merck, silica gel 60, $5 \mu \mathrm{m}$ ) was used for HPLC.

\subsection{Animal Material}

Specimens of the gorgonian corals Menella sp. were collected by trawling off the coast of southern Taiwan at a depth of $100 \mathrm{~m}$ in December 2004 and stored in a freezer until extraction. A voucher 
specimen (NMMBA-TW-GC-005) was deposited in the National Museum of Marine Biology and Aquarium, Taiwan. This organism was identified by comparison with previous descriptions [1].

\subsection{Extraction and Isolation}

The freeze-dried and minced material of Menella sp. (wet weight $451 \mathrm{~g}$, dry weight $411 \mathrm{~g}$ ) was extracted with ethyl acetate (EtOAc) at room temperature. The EtOAc layer $(5.07 \mathrm{~g})$ was separated on silica gel and eluted using $n$-hexane/EtOAc (stepwise from 100:1 to 0:100 $n$-hexane/EtOAc) to yield fractions 1-16. Fraction 3 was separated by normal-phase HPLC (NP-HPLC), using the mixtures of $n$-hexane and EtOAc (15:1-pure EtOAc) to yield the fractions $3 \mathrm{~A}-3 \mathrm{Z}$. Fraction $3 \mathrm{H}$ was purified by NP-HPLC using the mixtures of $n$-hexane and acetone (20:1) to afford 2 (1.0 mg). Compound 1 $(0.8 \mathrm{mg})$ was obtained from fraction $3 \mathrm{~S}$ by NP-HPLC ( $n$-hexane/EtOAc, 10:1).

Menelloide C (1): needle solid; mp 97-99 ${ }^{\circ} \mathrm{C}$; $\left([\alpha]_{\mathrm{D}}^{25}+57\left(c 0.04, \mathrm{CHCl}_{3}\right)\right.$; IR (neat) $v_{\max } 1744 \mathrm{~cm}^{-1}$; ${ }^{1} \mathrm{H}\left(\mathrm{CDCl}_{3}, 500 \mathrm{MHz}\right)$ and ${ }^{13} \mathrm{C}\left(\mathrm{CDCl}_{3}, 125 \mathrm{MHz}\right) \mathrm{NMR}$ data, see Table 1; ESIMS: $m / z 253[\mathrm{M}+\mathrm{Na}]^{+}$; HRESIMS: $m / z 253.1206$ (calcd for $\mathrm{C}_{15} \mathrm{H}_{18} \mathrm{O}_{2}+\mathrm{Na}, 253.1204$ ).

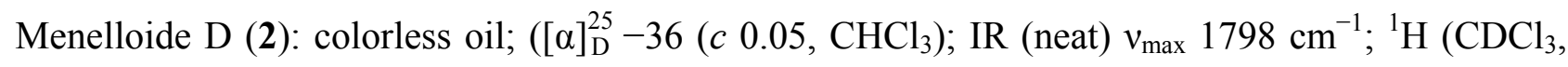
$500 \mathrm{MHz})$ and ${ }^{13} \mathrm{C}\left(\mathrm{CDCl}_{3}, 125 \mathrm{MHz}\right) \mathrm{NMR}$ data, see Table 3; ESIMS: $m / z 271[\mathrm{M}+\mathrm{Na}]^{+}$; HRESIMS: $m / z 271.1312$ (calcd for $\mathrm{C}_{15} \mathrm{H}_{20} \mathrm{O}_{3}+\mathrm{Na}, 271.1310$ ).

\subsection{Molecular Mechanics Calculations}

Implementation of the MM2 force field [16] in CHEM3D PRO software from CambridgeSoft Corporation (Cambridge, MA, USA; ver 9.0, 2005) was used to calculate molecular models.

\subsection{Elastase Release by Human Neutrophils}

Human neutrophils were obtained by means of dextran sedimentation and Ficoll centrifugation. Measurements of elastase release were carried out according to previously described procedures [17]. Elastase release experiments were performed using MeO-Suc-Ala-Ala-Pro-Valp-nitroanilide as the elastase substrate.

\section{Conclusions}

In previous studies, a series of interesting natural products, including steroids $[4,6,8]$, guaiane lactones [5,7], briarane diterpenoids [8], menellin A (a highly oxygenated racemate with C8 skeleton) [8], picolinic acid $N$-methyl betaine [3,4], $n$-hexadecanol [4], 9H-purin-6-amino- $N$-9-dimethyl [4], thymidine [4], and batyl alcohol [2,4], were isolated from gorgonian corals belonging to genus Menella, collected off the South China Sea. In our studies on the chemical constituents of a gorgonian coral identified as Menella sp., collected off the waters of Taiwan, various sesquiterpenoids featuring the guaiane, lindenane, and germacrane-type carbon skeletons, containing a $\gamma$-lactone in their structures, were isolated. As described in previous studies, the organic extract of Menella sp. displayed significant inhibitory effects on the generation of superoxide anion and the release of elastase $[9,10]$. However, at this stage, the results showed that the compounds that we isolated only showed weak 
activity. We suggested that the active components are still existed in the other fractions and these fractions will be studied in the future.

\section{Acknowledgments}

This research was supported by grants from the National Museum of Marine Biology and Aquarium (Grant No. 100100101 and 100200311); National Dong Hwa University; Division of Marine Biotechnology, Asia-Pacific Ocean Research Center, National Sun Yat-sen University (Grant No. 00C-0302-05); and the National Science Council (Grant No. NSC 100-2325-B-291-001, 99-2323-B-291-001, and 98-2320-B-291-001-MY3), Taiwan, awarded to P.-J.S.

\section{References and Notes}

1. Fabricius, K.; Alderslade, P. Soft Corals and Sea Fans-A Comprehensive Guide to the Tropical Shallow-Water Genera of the Central-West Pacific, the Indian Ocean and the Red Sea, 1st ed.; Australian Institute of Marine Science: Queensland, Australia, 2001; pp. 59-60, 206-207.

2. Deng, S.; Peng, S.; Li, F.; Tan, X.; Chen, J. A study on chemical constituents of South China Sea gorgonian Menella spinifera Kukenthal (I). Guangzhou Chem. 1993, 44-47.

3. Li, F.; Deng, S.; Rao, Z.; Wu, H.; Xu, J. Studies on chemical constituents of South China Sea gorgonian Menella spinifera Kukenthal (II). Guangzhou Chem. 1996, 49-51.

4. Deng, S.; Li, F.; Peng, S.; Rao, Z.; Wu, H.; Xu, J. Chemical constituents of the South China Sea gorgonian Menella spinifera Kukenthal. Chin. J. Appl. Chem. 1997, 14, 80-82.

5. Zhang, W.; Guo, Y.-W.; Mollo, E.; Cimino, G. Menverins A-D, new highly oxygenated guaiane lactones from Hainan gorgonian Menella verrucosa (Brundin). Helv. Chim. Acta 2004, 87, 2919-2925.

6. Zhang, W.; Huang, H.; Ding, Y.; Gavagnin, M.; Mollo, E.; Cimino, G.; Guo, Y.-W. Three polyoxygenated steroids from two species of the South China Sea gorgonian Muricella flexuosa and Menella verrucosa Brundin. Helv. Chim. Acta 2006, 89, 813-820.

7. Li, L.; Wang, C.-Y.; Huang, H.; Mollo, E.; Cimino, G.; Guo, Y.-W. Further highly oxygenated guaiane lactones from the South China Sea gorgonian Menella sp. Helv. Chim. Acta 2008, 91, 111-117.

8. Chai, X.-Y.; Sun, J.-F.; Tang, L.-Y.; Yang, X.-W.; Li, Y.-Q.; Huang, H.; Zhou, X.-F.; Yang, B.; Liu, Y. A novel cyclopentene derivative and a polyhydroxylated steroid from a South China Sea gorgonian Menella sp. Chem. Pharm. Bull. 2010, 58, 1391-1394.

9. Kao, S.-Y.; Chang, Y.-C.; Su, J.-H.; Lu, M.-C.; Chen, Y.-H.; Sheu, J.-H.; Wen, Z.-H.; Wang, W.-H.; Kuo, Y.-H.; Hwang, T.-L.; Sung, P.-J. (-)-Hydroxylindestrenolide, a new sesquiterpenoid from a gorgonian coral Menella sp. (Plexauridae). Chem. Pharm. Bull. 2011, 59, 1048-1050.

10. Kao, S.-Y.; Su, J.-H.; Hwang, T.-L.; Sheu, J.-H.; Su, Y.-D.; Lin, C.-S.; Chang, Y.-C.; Wang, W.-H.; Fang, L.-S.; Sung, P.-J. Discovery of novel sesquiterpenoids from a gorgonian Menella sp. Tetrahedron 2011, 67, 7311-7315.

11. Uchida, M.; Kusano, G.; Kondo, Y.; Nozoe, S.; Takemoto, T. Two new sesquiterpenoids from Chloranthus glaber Makino. Heterocycles 1978, 9, 139-144. 
12. Uchida, M.; Koike, Y.; Kusano, G.; Kondo, Y.; Nozoe, S.; Kabuto, C.; Takemoto, T. Studies on the constituents of Chloranthus spp. III. Six sesquiterpenes from Chlorantus japonicus. Chem. Pharm. Bull. 1980, 28, 92-102.

13. The optical rotation value for chloranthalactone B (7) was reported as $[\alpha]-130.3$ in the text of ref. 12 . However, in the text of ref. 11 and in the experimental of ref. 12, the optical rotation values for chloranthalactone B (4) were reported as $[\alpha]-1303.3$. The authors suggested that the optical rotation value $[\alpha]-1303.3$ are typing errors in the text of ref. 11 and in the experimental of ref. 12.

14. Kawabata, J.; Tahara, S.; Mizutani, J.; Furusaki, A.; Hashiba, N.; Matsumoto, T. Shizukanolides, two sesquiterpenoids from Chloranthus japonicus (Chloranthaceae). Agric. Biol. Chem. 1979, 43, 885-887.

15. Kawabata, J.; Tahara, S.; Mizutani, J. Isolation and structural elucidation of four sesquiterpenes from Chloranthus japonicus (Chloranthaceae). Agric. Biol. Chem. 1981, 45, 1447-1453.

16. Allinger, N.L. Conformational analysis. 130. MM2. A hydrocarbon force field utilizing $V_{1}$ and $V_{2}$ torsional terms. J. Am. Chem. Soc. 1977, 99, 8127-8134.

17. Hwang, T.-L.; Su, Y.-C.; Chang, H.-L.; Leu, Y.-L.; Chung, P.-J.; Kuo, L.-M.; Chang, Y.-J. Suppression of superoxide anion and elastase release by $\mathrm{C}_{18}$ unsaturated fatty acids in human neutrophils. J. Lipid Res. 2009, 50, 1395-1408.

Samples Availability: Not available.

(C) 2011 by the authors; licensee MDPI, Basel, Switzerland. This article is an open access article distributed under the terms and conditions of the Creative Commons Attribution license (http://creativecommons.org/licenses/by/3.0/). 